\title{
Cerebellar and Brainstem Hypometabolism in Olivopontocerebellar Atrophy Detected with Positron Emission Tomography
}

\author{
Sid Gilman, MD, ${ }^{*}$ Dorene S. Markel, MS, ${ }^{*}$ Robert A. Koeppe, PhD, $\dagger$ Larry Junck, MD,* \\ Karen J. Kluin, MS, $\ddagger$ Stephen S. Gebarski, MD, $\S$ and Richard D. Hichwa, $\mathrm{PhD} \dagger$
}

We studied local cerebral metabolic rates for glucose (ICMRglc) with ${ }^{18}$ F-2-fluoro-2-deoxy-D-glucose and positron emission tomography (PET) in 30 patients with olivopontocerebellar atrophy (OPCA) and 30 age-matched control subjects without neurological disease. The diagnosis of OPCA was based on the history and physical findings and on the exclusion of other causes of cerebellar ataxia by means of laboratory investigations. Computed tomographic scans revealed some degree of atrophy of the cerebellum in most patients with OPCA, and many also had atrophy of the brainstem. PET studies in these patients revealed significant hypometabolism in the cerebellar hemispheres, cerebellar vermis, and brainstem in comparison with the normal control subjects. A significant relationship was found between the degree of atrophy and the level of ICMRglc in the cerebellum and brainstem. Nevertheless, several patients had minimal atrophy and substantially reduced ICMRglc, suggesting that atrophy does not fully account for the finding of hypometabolism. ICMRglc was within normal limits for the thalamus and cerebral cortex. The data suggest that PET/ ICMRglc may be useful as a diagnostic test in patients with the adult onset of cerebellar ataxia.

Gilman S, Markel DS, Koeppe RA, Junck L, Kluin KJ, Gebarski SS, Hichwa RD. Cerebellar and brainstem hypometabolism in olivopontocerebellar atrophy detected with positron emission tomography.

Ann Neurol 1988;23:223-230

Olivopontocerebellar atrophy (OPCA) is a progressive neurological disorder characterized by neuronal degeneration in the cerebellar cortex, pons, and inferior olives [1-4]. The disease occurs both sporadically and genetically, with either autosomal dominant or autosomal recessive transmission. Based on pathological findings at necropsy, OPCA is one of three adult-onset idiopathic degenerative diseases involving the cerebellum, the other two being cerebellar-olivary degeneration (COD) [4, 5-7] and parenchymatous cerebellar cortical atrophy (CCA) $[2,6,8]$. These three types of cerebellar degeneration are difficult to distinguish clinically without neuropathological confirmation in sporadic cases or neuropathological verification in at least one afflicted family member in cases with hereditary transmission. It has been argued that pathological classifications should not be used for clinical categorization of the cerebellar ataxias [2]. Nevertheless, the term $O P C A$ is firmly established in the clinical diagnostic nomenclature for patients with idiopathic cerebellar degeneration [9], even though some cases of OPCA described clinically actually may be revealed as cases of COD or CCA on ultimate pathological examination.

OPCA is characterized by a progressive cerebellar ataxia, usually beginning with a disorder of gait and dysarthria and later evolving into a severe disturbance of coordinated movements of all the limbs. Frequently associated clinical features described in the literature include ophthalmoplegia; optic atrophy; pigmentary retinal degeneration; dementia; extrapyramidal abnormalities, including rigidity, chorea, and athetosis; amyotrophy of the limbs or tongue; and symptoms of bulbar degeneration [1-4]. At times OPCA includes a widespread multisystem atrophy involving elements of the Shy-Drager syndrome with a combination of cerebellar ataxia, extrapyramidal disease, and autonomic insufficiency.

The diagnosis of OPCA is usually based on clinical evaluation because most laboratory investigations show no abnormalities. Cerebrospinal fluid (CSF) protein may be slightly elevated and the electroencephalogram (EEG) may show an excessive amount of slow activity [10]. The computed tomographic (CT) scan
From the Departments of *Neurology, †Internal Medicine, $¥$ Physical Medicine and Rehabilitation, and \&Radiology, The University of Michigan, Ann Arbor, MI.

Received Apr 20, 1987, and in revised form Jul 28. Accepted for publication Sep 17, 1987.
Address correspondence to Dr Gilman, The University of Michigan, Department of Neurology, 1914/0316 Taubman Health Care Center, 1500 E Medical Center Dr, Ann Arbor, MI 48109-0316. 
shows evidence of cerebellar and sometimes brainstem atrophy in approximately 50\% of patients [2]. Auditory evoked potentials are abnormal in some patients [11], and impaired sensory nerve conduction has been reported [12, 13]. Immunological and biochemical investigations in OPCA usually show normal results, though a deficiency of glutamate dehydrogenase has been reported in the fibroblasts and platelets of some patients with an autosomal recessive form of the disorder [14-21].

A progressive cerebellar disorder in adult life can result from many disease processes, including malformations, degenerations, vascular diseases, infections, neoplasms, remote effects of neoplasms, toxic/metabolic disorders, and demyelinating disease. The diagnosis of OPCA or one of the other adult-onset degenerative diseases is usually suggested by the presence of atrophy of the cerebellum and brainstem on CT scanning, often in association with abnormalities of brainstem auditory evoked responses and peripheral nerve studies. None of these tests is diagnostic for OPCA, and an extensive evaluation usually is needed to rule out the many other possible causes of progressive ataxia in an adult.

Positron emission tomography (PET) scanning is a noninvasive imaging technique used to examine biochemical or physiological processes of the body such as metabolic activity of the central nervous system, blood flow, neurotransmitter activity, and neurotransmitter receptor density. The present investigation was initiated to study the metabolic activity of the central nervous system in OPCA and to develop a noninvasive test that will be helpful in the diagnosis of this condition. At present, in the absence of a positive family history or in the presence of a positive family history but without autopsy confirmation, the diagnosis of OPCA can be made only by excluding other causes of cerebellar disease. If a distinctive pattern of metabolic activity can be detected in OPCA with PET scanning, this procedure may provide a noninvasive method of helping to establish the diagnosis. In families known to have OPCA, PET scanning may be used to detect individuals with the disease in advance of the onset of symptoms. In addition, PET scanning may provide a means of detecting involvement of structures other than the cerebellum and its connections in patients with OPCA who have multisystem involvement. Preliminary findings from this study have been published $[22,23]$.

\section{Methods}

The individuals studied consisted of 30 patients with OPCA and 30 normal control subjects (Table 1). The studies were approved by the institutional review board of the University of Michigan Medical Center, and informed consent was obtained from all subjects. The normal control subjects had no
Table 1. Average Ages of the Subjects Studied

\begin{tabular}{llllll} 
& & & Control Subjects & & \multicolumn{2}{c}{$\begin{array}{c}\text { Patients with } \\
\text { OPCA }\end{array}$} \\
\cline { 2 - 3 } \cline { 5 - 6 } & $\mathrm{n}$ & Age $( \pm$ SD $)$ & & $\mathrm{n}$ & Age $( \pm$ SD $)$ \\
\hline Male & 14 & $49( \pm 17)$ & & 13 & $53( \pm 13)$ \\
Female & 16 & $49( \pm 8)$ & & 17 & $53( \pm 14)$ \\
All subjects & 30 & $49( \pm 13)$ & & 30 & $53( \pm 13)$ \\
\hline
\end{tabular}

OPCA = olivopontocerebellar atrophy.

history of neurological disease and no important abnormalities on neurological and general physical examination. These subjects were taking no medications known to affect central nervous system (CNS) function or to cause CNS side effects. The diagnosis of OPCA was made on the basis of the history, physical examination, neurological examination, laboratory tests to exclude other diseases, and the findings on CT scans. None of the patients with OPCA had disorders of sensory function adequate to cause ataxia of movement. The laboratory tests included complete blood counts; serum profiles of hepatic and renal functions; brainstem auditory, visual, and somatosensory evoked potentials; serum levels of vitamin $\mathrm{E}, \mathrm{B}_{12}$, and folic acid; and studies of thyroid function. A search conducted for an occult malignancy included a pelvic examination in the women, a prostate examination in the men, determination of acid phosphatase levels, stool guaiac tests for occult blood, and chest $\mathrm{x}$-ray films.

Normal control subjects and OPCA patients were studied in the University of Michigan Cyclotron/P.E.T. Facility while lying supine, awake, and blindfolded in a quiet room. Scans were performed 30 to 75 minutes after injection of ${ }^{18} \mathrm{~F}-2$ fluoro-2-deoxy-D-glucose $\left({ }^{18} \mathrm{~F}\right.$-FDG). ${ }^{18} \mathrm{~F}$-FDG was synthesized by a modification of the method of Ehrenkaufer and colleagues [24]. Radiochemical purity was greater than $95 \%$. Five to ten millicuries were injected intravenously and PET scans were performed with a TCC PCT $4600 \mathrm{~A}$ tomograph having an in-plane resolution of $11 \mathrm{~mm}$ full width at half maximum (FWHM) and a Z-axis resolution of $9.5 \mathrm{~mm}$ FWHM. Five planes with 11.5 -mm center-to-center separation were imaged simultaneously. Four sets of scans were taken per patient, including two interleaved sets through lower brain levels and two interleaved sets through higher brain levels for a total of 20 slices, each separated by 5.75 $\mathrm{mm}$. Attenuation correction was calculated by the standard ellipse method, modified to account for attenuation from the head holder and skull.

Blood samples were collected from the radial artery. Local cerebral metabolic rate for glucose (ICMRglc) was calculated using a three-compartment model and single scan approximation described by Phelps and associates [25] with graymatter kinetic constants derived from normal subjects [26]. Regions of interest (ROIs) were studied in the cerebellar hemispheres, vermis, brainstem, thalamus, and cerebral cortex. Data were collected from the ROIs by placing a $22 \times 11$ $\mathrm{mm}$ parallelogram over each cerebellar hemisphere, an $11 \times$ $18 \mathrm{~mm}$ rectangle over the vermis, an $11 \times 15 \mathrm{~mm}$ rectangle over the brainstem, and an $11 \times 11 \mathrm{~mm}$ square over each thalamus (Fig 1A, B). Each ROI was centered over a local peak in ICMRglc. (For reference, an individual image ele- 


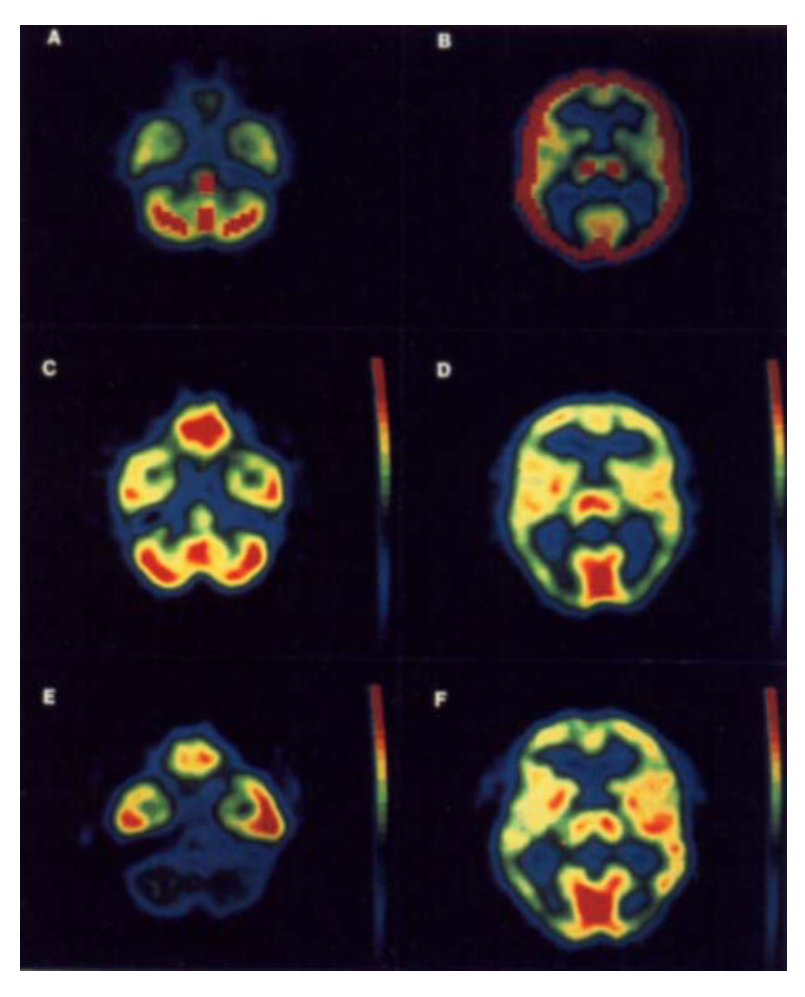

Fig 1. Positron emission tomography scans showing cerebral glucose utilization as detected with ${ }^{18} F-2-f$ luoro-2-deoxy-D-glucose. Scans in $A, C$, and $E$ show a borizontal section at the level of the cerebellum and the base of the temporal and frontal lobes. Scans in B, D, and $F$ show the level of the basal ganglia and thalamus. Color bars in $C, D, E$, and $F$ indicate the rate of glucose utilization $(\mathrm{mg} / 100 \mathrm{gm} / \mathrm{min}) .(A, B)$ Control subject. Location of regions of interest in the cerebellar vermis, cerebellar hemispheres, and brainstem $(A)$ and in the thalamus and cerebral cortex $(B) .(C, D)$ Male control subject age 58. Note that the glucose utilization rates in the cerebellum are approximately the same as in the temporal and frontal lobes. Color bars indicate glucose utilization rates $(\mathrm{mg} / 100 \mathrm{gm} / \mathrm{min})$ extending from 0.0 to $7.5(C)$ and 0.0 to 9.5 (D). (E, F) Male patient age 50 with olivopontocerebellar atropby of 5 years' duration. Note the marked degree of hypometabolism in the cerebellar vermis, cerebellas hemispheres, and brainstem $(E)$ but the normal pattern of metabolic activity in the cerebral cortex, basal ganglia, and thalamus $(F)$. Color bars indicate glucose utilization rates $(\mathrm{mg}$ / $100 \mathrm{gm} / \mathrm{min}$ ) extending from 0.0 to $7.5(\mathrm{E})$ and 0.0 to $9.5(\mathrm{~F})$.

ment [pixel] is $3.75 \mathrm{~mm} \times 3.75 \mathrm{~mm}$ in size.) Data were obtained from two slices containing the cerebellum and brainstem and from one slice containing the thalamus. ROIs from the cerebellar vermis were posterior to the fourth ventricle. The brainstem ROI chiefly reflects the pons, but the mesencephalon or medulla oblongata could be partially represented. Data from the cerebral cortex were obtained by measuring ICMRglc in the cortical ribbon from five consecutive slices, beginning with the lowest slice containing the basal ganglia. This was accomplished using a computerized routine that enhances the contrast in the images, then selects a band $15 \mathrm{~mm}$ wide extending inward from the cortical rim.
Table 2. Rating Scales for Evaluating

the Degree of Atrophy in Computed Tomographic Scans

\begin{tabular}{ll}
\hline Cerebellum & Brainstem \\
\hline 0-Normal & 0-Normal \\
1-Atrophy in single folium & 1 -Mild atrophy \\
2-Atrophy in two folia & 2-Moderate atrophy \\
3-Mild atrophy in all folia & 3 -Severe atrophy \\
4-Moderate atrophy in all folia & \\
5-Severe atrophy in all folia & \\
\hline
\end{tabular}

The mean metabolic rate was computed for each of these ROIs.

CT scans were obtained in OPCA patients with a GE 9800 instrument. The scans were read by a neuroradiologist (S.S.G.) who was informed only of the patient's age and diagnosis. The neuroradiologist was unaware of the patient's clinical history or findings on PET study. A rating scale was devised to quantitate the degree of atrophy in each cerebellar hemisphere, the cerebellar vermis, and the brainstem (Table 2).

Student's $t$ test was used for statistical analysis of the data to compare the patients who had OPCA with a group of ageand sex-matched control subjects. A Spearman rank correlation test was used to assess the relationship between CT rating and ICMRglc.

\section{Results}

\section{Clinical Cbaracteristics}

The patients with OPCA consisted of 13 men and 17 women with an average duration of illness of $6 \pm 5$ years and a range from 1 to 22 years. Fourteen patients had a family history of a similar illness in first-degree relatives, and 16 were sporadic cases. Among the patients with a positive family history, all except 1 had a history compatible with autosomal dominant transmission. One patient's history was compatible with autosomal recessive transmission.

The patients all presented with complaints of difficulty in walking. Most also had complaints of speech disorder and incoordination of limb movements, causing difficulty with fine movements such as handwriting. Examination in all patients revealed ataxia of gait and of limb movements ranging from mild to severe. Seven regularly used a wheelchair because of severe ataxia. Most had abnormal extraocular movements, including saccadic pursuit movements, overshoot dysmetria, and gaze paretic nystagmus. All had dysarthria with a combination of ataxic and spastic speech characteristics. Nine patients had limb spasticity, 6 had hyperreflexia, and 8 had extensor plantar responses, but only 2 had limb spasticity, hyperreflexia, and extensor plantars. One patient had features of parkinsonism, with akinesia, masked face, and tremor, as well as symptomatic postural hypotension. 
Table 3. Local Cerebral Metabolic Rates for Glucose (mg/100 gm/min) in All Subjects ${ }^{2}$

\begin{tabular}{lll}
\hline Structure & Control Subjects & $\begin{array}{l}\text { Parients with } \\
\text { OPCA }^{\mathrm{b}}\end{array}$ \\
\hline $\begin{array}{l}\text { Cerebellar vermis } \\
\text { Left cerebellar hemi- } \\
\text { sphere }\end{array}$ & $5.34 \pm 1.12$ & $3.77 \pm 0.98^{\mathrm{c}}$ \\
$\begin{array}{l}\text { Right cerebellar hemi- } \\
\quad \text { sphere }\end{array}$ & $5.84 \pm 1.35$ & $4.20 \pm 1.13^{\mathrm{c}}$ \\
$\begin{array}{l}\text { Brainstem } \\
\begin{array}{l}\text { Thalamus } \\
\text { Cerebral cortex }\end{array}\end{array}$ & $4.38 \pm 0.86$ & $3.19 \pm 1.14^{\mathrm{c}}$ \\
\hline
\end{tabular}

"Values given are the mean $\pm S D$.

$b_{n}=30$.

${ }^{c} p<0.001$.

OPCA = olivopontocerebellar atrophy.

\section{PET Studies}

The scans of patients with OPCA in comparison with those of the normal control subjects showed decreased glucose metabolic activity in the cerebellar hemispheres, vermis, and brainstem, with no obvious abnormality of activity in other portions of the brain (Fig $1 \mathrm{C}-\mathrm{F}$ ). Means and standard deviations (SD) of ICMRglc in patients with OPCA compared to those of control subjects appear in Table 3. ICMRglc is significantly decreased in patients with OPCA in the cerebellar hemispheres, cerebellar vermis, and brainstem. There is no significant difference between control subjects and OPCA patients for ICMRglc in the thalamus or cerebral cortex. With the data normalized to the cerebral cortex, ICMRglc in OPCA patients again is significantly decreased in the cerebellar hemi-
Table 4. Local Cerebral Metabolic Rates for Glucose Normalized to the Cerebral Cortex in All Subjects ${ }^{\mathrm{a}}$

\begin{tabular}{lll}
\hline Structure & Control Subjects & $\begin{array}{l}{ }^{\mathrm{P}} \\
\mathrm{OPCA}^{\mathrm{b}}\end{array}$ \\
\hline $\begin{array}{l}\text { Cerebellar vermis } \\
\text { Left cerebellar hemi- } \\
\quad \text { sphere }\end{array}$ & $0.92 \pm 0.08$ & $0.66 \pm 0.16^{\mathrm{c}}$ \\
$\begin{array}{l}\text { Right cerebellar hemi- } \\
\text { sphere }\end{array}$ & $1.03 \pm 0.11$ & $0.74 \pm 0.16^{\mathrm{c}}$ \\
$\begin{array}{l}\text { Brainstem } \\
\text { Thalamus }\end{array}$ & $0.76 \pm 0.06$ & $0.74 \pm 0.17^{\mathrm{c}}$ \\
\hline
\end{tabular}

${ }^{a}$ Values given are the mean $\pm \mathrm{SD}$.

${ }^{b} \mathbf{n}=30$.

${ }^{c} p<0.001$.

OPCA = olivopontocerebellar atrophy.

spheres, cerebellar vermis, and brainstem, while remaining within normal limits in the thalamus (Table 4).

Figure 2 shows the mean ICMRglc normalized to the cerebral cortex for the brainstem, cerebellar vermis, cerebellar hemispheres, and thalamus in each patient with OPCA and normal control subject. This figure demonstrates that $1 \mathrm{CMRglc}$ in these patients is more than 2 SD below the mean of normal control subjects in 19 of 30 cases for the brainstem, 21 for the

Fig 2. Graphs of local cerebral metabolic rate for glucose (LCMRG) normalized to the cerebral cortex in normal control subjects as compared to patients with olivopontocerebellar atrophy (OPCA). Each point represents the average value for each case in the structure specified. The solid borizontal lines depict the mean value for each group and the broken borizontal lines indicate the limits of 2 SD of the means for the normal volunteers.

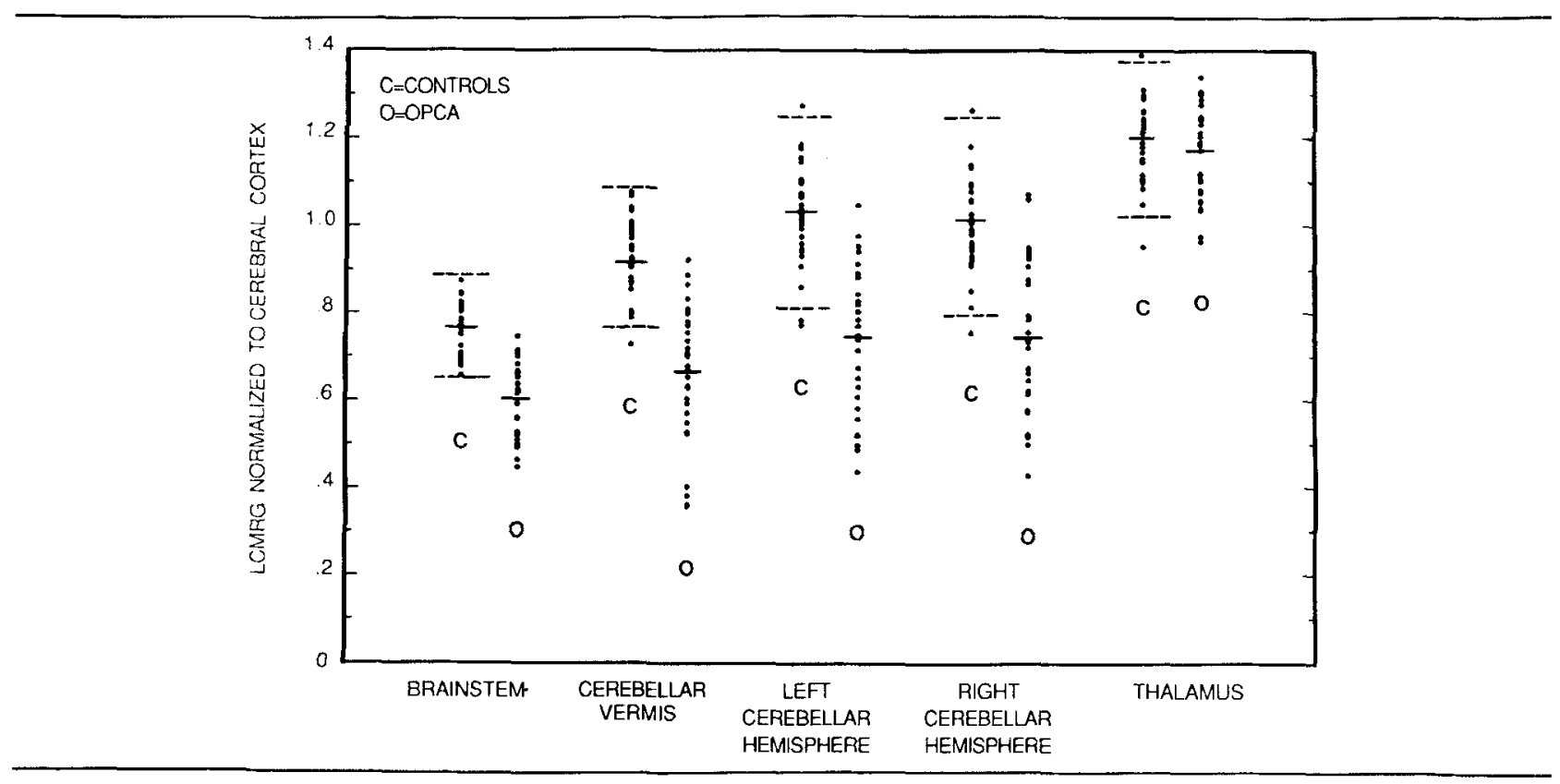


Table 5. Local Cerebral Metabolic Rates for Glucose $(\mathrm{mg} / 100 \mathrm{gm} / \mathrm{min})$ in Males

\begin{tabular}{|c|c|c|}
\hline Structure & Control Subjects $^{b}$ & $\begin{array}{l}\text { Patients with } \\
\text { OPCA }^{c}\end{array}$ \\
\hline Cerebellar vermis & $5.19 \pm 1.13$ & $3.48 \pm 0.91^{\mathrm{d}}$ \\
\hline $\begin{array}{l}\text { Left cerebellar hemi- } \\
\text { sphere }\end{array}$ & $5.78 \pm 1.27$ & $3.91 \pm 0.91^{d}$ \\
\hline $\begin{array}{l}\text { Right cerebellar hemi- } \\
\text { sphere }\end{array}$ & $5.67 \pm 1.28$ & $3.85 \pm 0.95^{d}$ \\
\hline Brainstem & $4.29 \pm 0.79$ & $3.32 \pm 0.68^{e}$ \\
\hline Thalamus & $6.74 \pm 1.13$ & $6.54 \pm 1.48$ \\
\hline Cerebral cortex & $5.77 \pm 0.94$ & $5.55 \pm 0.98$ \\
\hline
\end{tabular}

${ }^{2} \mathrm{Values}$ given are the mean $\pm \mathrm{SD}$.

$b_{n}=14$

${ }^{n} \mathbf{n}=13$.

${ }^{d} p<0.001$.

${ }^{e} p<0.01$.

OPCA $=$ olivopontocerebellar atrophy.

Table 6. Local Cerebral Metabolic Rates for Glucose (mg/100 gm/min) in Females ${ }^{\mathbf{a}}$

\begin{tabular}{lll}
\hline Structure & Control Subjects & $\begin{array}{l}\text { Patients with }^{\mathrm{O}} \\
\text { OPCA }^{\mathrm{c}}\end{array}$ \\
\hline $\begin{array}{l}\text { Cerebellar vermis } \\
\text { Left cerebellar hemi- } \\
\text { sphere }\end{array}$ & $5.46 \pm 1.13$ & $3.98 \pm 1.01^{\mathrm{d}}$ \\
$\begin{array}{l}\text { Right cerebellar hemi- } \\
\quad \text { sphere }\end{array}$ & $6.00 \pm 1.43$ & $4.42 \pm 1.26^{\mathrm{d}}$ \\
$\begin{array}{l}\text { Brainstem } \\
\text { Thalamus }\end{array}$ & $4.45 \pm 0.94$ & $4.46 \pm 1.23^{\mathrm{d}}$ \\
Cerebral cortex & $6.97 \pm 1.29$ & $6.85 \pm 0.87^{\mathrm{e}}$ \\
\hline
\end{tabular}

a Values given are the mean $\pm S D$.

${ }^{b} \mathrm{n}=16$.

${ }^{\mathrm{c}} \mathrm{n}=17$.

$\mathrm{d} p<0.001$.

${ }^{e} p<0.01$.

vermis, and 17 (right) to 19 (left) for the cerebellar hemispheres.

In 24 of the 30 patients with OPCA, at least one cerebellar or brainstem region showed ICMRglc values, normalized to cerebral cortex, to be decreased below 2 SD from the mean of the control subjects. Thus, $80 \%$ of patients with OPCA had at least one markedly hypometabolic region detected by PET. Only 2 control subjects had one or more regions below $2 \mathrm{SD}$ from the mean of the normal group, indicating a false-positive rate of $6.7 \%$ in using the above criteria for detection of cerebellar and brainstem hypometabolism with PET.

ICMRglc was determined separately in male and female subjects, and the results showed significant decreases of ICMRglc in the cerebellar hemispheres, cerebellar vermis, and brainstem in patients of both sexes (Tables 5 and 6). The age of onset and duration
Table 7. Comparison of Patients with Sporadic and Familial OPCA

\begin{tabular}{lcc}
\hline & Sporadic & Familial \\
\hline Age (yr) & $57 \pm 11$ & $48 \pm 14$ \\
Males & 9 & 4 \\
Females & 7 & 10 \\
Duration of symptoms (yr) & $6 \pm 5$ & $7 \pm 6$ \\
Age of onset of symptoms & $50 \pm 16$ & $41 \pm 15$ \\
\hline
\end{tabular}

OPCA = olivopontocerebellar atrophy.

Table 8. Local Cerebral Metabolic Rates for Glucose ( $\mathrm{mg} / 100 \mathrm{gm} / \mathrm{min}$ ) in Sporadic OPCA as Compared with Those in Familial OPCA

\begin{tabular}{lll}
\hline Structure & Sporadic $^{\mathrm{b}}$ & Familial $^{\mathrm{c}}$ \\
\hline Cerebellar vermis & $3.41 \pm 0.77$ & $4.17 \pm 1.07^{\mathrm{d}}$ \\
Left cerebellar hemisphere & $3.82 \pm 0.79$ & $4.64 \pm 1.33^{\mathrm{d}}$ \\
Right cerebellar hemisphere & $3.86 \pm 0.83$ & $4.57 \pm 1.35^{\mathrm{d}}$ \\
Brainstem & $3.32 \pm 0.60$ & $3.60 \pm 0.96$ \\
Thalamus & $6.67 \pm 1.40$ & $6.70 \pm 1.46$ \\
Cerebral cortex & $5.54 \pm 0.92$ & $5.98 \pm 1.40$ \\
\hline
\end{tabular}

${ }^{2}$ Values given are the mean $\pm S D$.

$\mathrm{b}_{\mathrm{n}}=16$.

$c_{n}=14$.

$\mathrm{d} p<0.05$.

OPCA = olivopontocerebellar atrophy.

of the disease were not correlated with cerebellar ICMRglc. We compared ICMRglc in patients with and without signs of corticospinal tract involvement as manifested by spasticity, hyperreflexia, or extensor plantar responses and found no significant difference. We examined ICMRglc in patients with sporadic (as compared with familial) OPCA (Tables 7 and 8). The mean ICMRglc is consistently lower in the sporadic cases and reaches statistical significance at the $95 \%$ confidence level for the cerebellar vermis and hemispheres, but not for the brainstem.

\section{CT Scans}

The CT scans of the patients with OPCA showed variable degrees of atrophy of the cerebellum and brainstem (Fig 3). In some, the atrophy was within normal limits for the patient's age. In most, however, the cerebellum showed focal or generalized atrophy of the folia, with enlargement of the sulci and dilatation of the fourth ventricle, and the brainstem was smaller than normal for the age of the parient. The cerebral hemispheres generally appeared normal for the age of the patient.

The degree of atrophy in the cerebellar vermis, cerebellar hemispheres, and brainstem was quantitated with rating scales, and the resulting data were plotted against lCMRglc. Figure 4 shows the mean lCMRglc in 


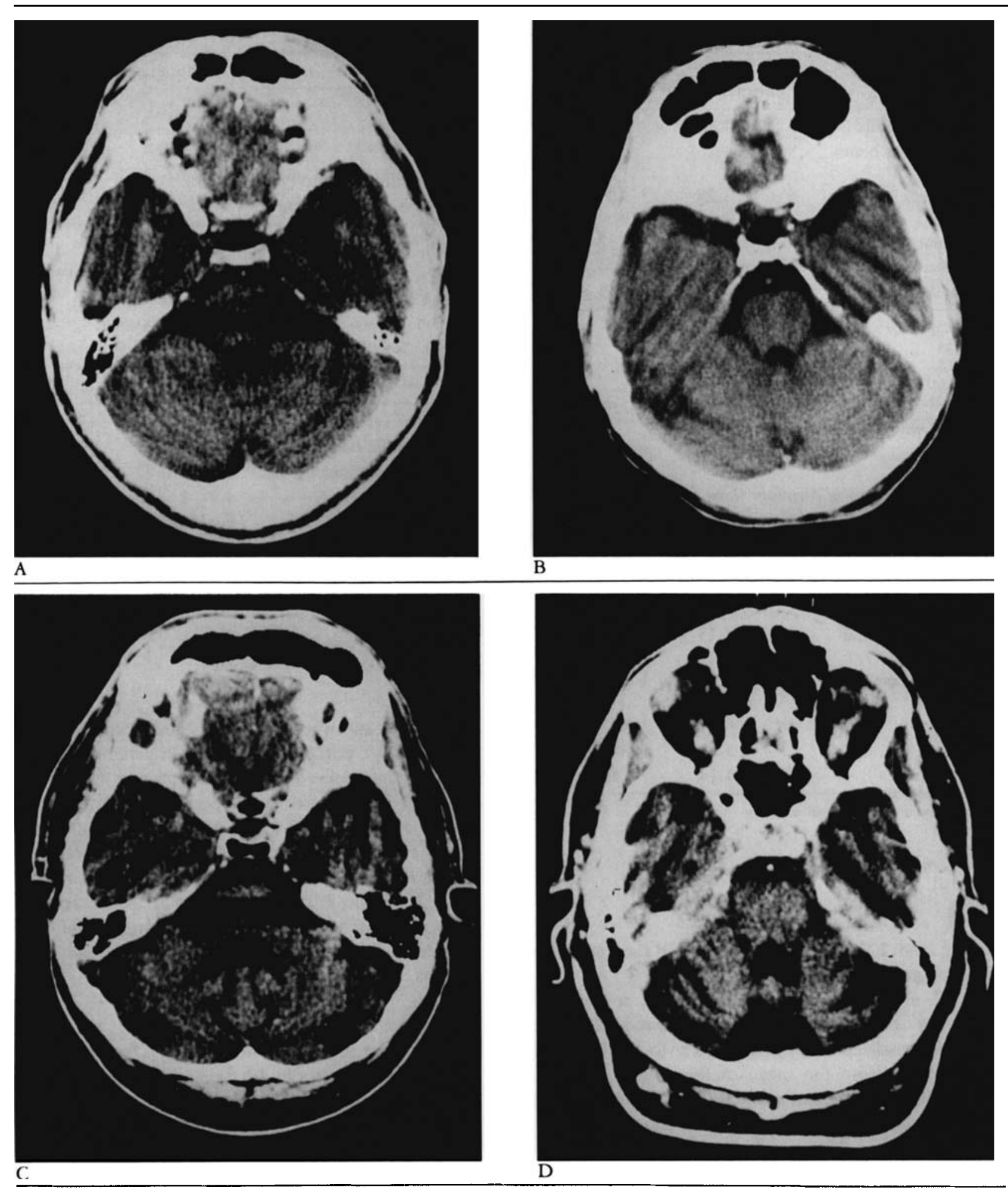

Fig 3. (A) Computed tomographic (CT) scan of a 65-year-old man with olivopontocerebellar atrophy (OPCA) of 2 years' duration showing minimal atropby. (B) CT scan of a 55-year-old man with OPCA of 4 years' duration showing mild atropby. (C) CT scan of a 66-year-old man with OPCA of 4 years' duration showing moderate atrophy. (D) CT scan of a 57-yearold man with OPCA of 20 years' duration showing severe atrophy. 


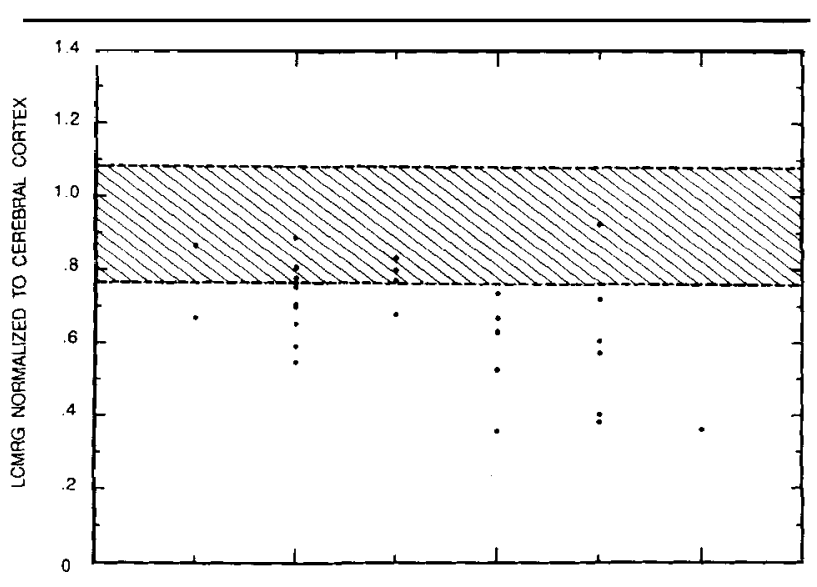

CT RATING

Fig 4. Graph of mean local cerebral metabolic rate for glucose (LCMRG) in the cerebellar vermis normalized to the cerebral cortex plotted against the degree of atrophy in the cerebellar vermis observed in computed tomographic (CT) scans of 30 patients with olivopontocerebellar atrophy. The criteria used in the rating scales for evaluating the degree of atropby in CT scans are shown in Table 2. These data demonstrate a strong relationship between $L C M R G$ and the degree of atropby of cerebellar tissue $(\mathrm{r}=$ $-0.479, \mathrm{p}<0.01$ ). The shaded region demarcates the range of $2 S D$ of LCMRG in the control group.

the cerebellar vermis normalized to the cerebral cortex, plotted against the CT ratings for atrophy in the cerebellar vermis for all patients with OPCA. Testing these data with the Spearman rank correlation reveals a significant relationship for the cerebellar vermis $(r=$ $-0.479, p<0.01$ ) and also for the cerebellar hemispheres $(r=-0.435, p<0.01$ [left]; $r=-0.535, p$ $<0.01$ [right]) and brainstem $(r=-0.400, p<0.05)$. The shaded region in Figure 4 indicates the range of 2 SD of ICMRglc in the normal control group. This shows that several patients with OPCA have marked hypometabolism but only minor degrees of atrophy.

\section{Discussion}

The diagnosis of OPCA is a clinical one based on the history and neurological examination, the demonstration of cerebellar and often brainstem atrophy in CT scans, and the absence of other conditions causing cerebellar ataxia. In this study, we carefully selected patients in whom the diagnosis of OPCA seemed extremely likely. All patients in our study had ataxia that affected gait, limb coordination, extraocular movements, and speech. The speech disorders were characterized by a mixture of ataxic and spastic dysarthria, with a predominance of ataxic dysarthria in most. The majority of patients had a pure cerebellar ataxia without clinical signs of involvement of other CNS structures, although 11 had evidence of corticospinal tract involvement, with hyperreflexia and extensor plantar responses, and 1 had symptoms and signs of parkin- sonism. We had no patients with chorea, myoclonus, retinal degeneration, or ophthalmoplegia.

PET studies of our patients revealed significantly decreased ICMRglc in the cerebellar hemispheres, vermis, and brainstem in comparison with age- and sexmatched control subjects. No abnormality of ICMRglc was found in the cerebral cortex or thalamus. Thus, the abnormality appears to be specific for the cerebellum and its brainstem connections. The in-plane resolution of the scanner used in these studies is approximately $11 \mathrm{~mm}$, and the vermis and brainstem are only slightly larger than this. Nevertheless, recovery of activity from these structures is both stable and high. The vermal region and the brainstem can be identified easily, and their values are close to the values found in the cerebellar hemispheres. Our measurements of the vermis are taken posterior to the fourth ventricle, so that partial volume averaging from that structure should contribute only slightly to our measurements.

The basis for the decreased metabolic activity is probably a decrease in the number of axons, synaptic terminals, and cell bodies in the structures under investigation. This seems likely because the patients' $C T$ scans showed variable degrees of atrophy in the brainstem and cerebellum. Moreover, a significant relationship was found between the degree of atrophy in the cerebellum and brainstem and the metabolic rates of these tissues. This finding raises the possibility that the apparent hypometabolism in the cerebellum and brainstem results from partial volume effects, that is, decreased tissue mass and increased amounts of cerebrospinal fluid in the tissues under investigation. The surviving synaptic connections could have decreased or normal metabolism. The finding that several patients with OPCA have significant hypometabolism with minor degrees of atrophy suggests that atrophy with partial volume averaging does not fully account for the degree of hypometabolism detected. At present, we are not able to determine with certainty to what extent the decreased ICMRglc values represent decreased metabolism per gram of viable tissue and to what extent they reflect decreased tissue mass with partial volume averaging. This determination will be assisted by the development of more refined and objective methods of evaluating atrophy, a task that is currently in progress [27].

The findings in this study correspond well to the major neuropathological abnormalities observed on examination of the brain in OPCA. These consist of degenerative changes in the cerebellar vermis and hemispheres, pons, and inferior olives $[1,2,6,28,29]$. On microscopic examination, most cases show a variable loss of Purkinje cells, a reduction in the number of cells in the molecular and granular layers, demyelination of the middle cerebellar peduncle, and marked loss of cells in the pontine nuclei and olives. Many 
other structures in the CNS frequently are affected, including Clarke's column; anterior horn cells of the spinal cord; corticospinal and spinocerebellar tracts; posterior columns; multiple brainstem nuclei, including the cuneate, gracile, hypoglossal, vestibular, facial, trigeminal, and oculomotor nuclei; dentate nucleus; red nucleus; substantia nigra; and globus pallidus [1, 2]. The neuropathological findings in OPCA vary substantially between patients and between families.

The present study demonstrates that PET appears to be a highly useful test in establishing the diagnosis of OPCA. In about two-thirds of patients with OPCA, ICMRglc in the brainstem and vermis was below $2 \mathrm{SD}$ from the mean of the normal volunteers. Moreover, in $80 \%$ of patients with OPCA, at least one cerebellar or brainstem region had ICMRglc values, normalized to the cerebral cortex, that were decreased below $2 \mathrm{SD}$ from the mean of control subjects. The scans of only 2 control subjects showed this abnormality, indicating a false-positive rate of less than $7 \%$. Thus, the test has a relatively high sensitivity and a low false-positive rate. The specificity of the finding of cerebellar and brainstem hypometabolism in the pattern shown in this study is unclear. Determination of specificity awaits studies on patients with other diseases affecting the cerebellum, including cerebellar degeneration from alcohol and from the remote effects of neoplasms.

Supported in part by NIH grants NS-15655 and NS-00908. We are indebted to the staff of the Cyclotron/P.E.T. Facility and to Guy Rosenthal for their assistance with this study.

\section{References}

1. Gilman S, Bloedel JR, Lechtenberg R. Disorders of the cerebellum. Philadelphia: Davis, 1981

2. Harding AE. The hereditary ataxias and related disorders. London: Churchill Livingstone, 1984

3. Eadie MJ. Olivo-ponto-cerebellar atrophy (Dejerine-Thomas type). In: Vinken PJ, Bruyn GW, eds. Handbook of clinical neurology. Amsterdam: North-Holland, 1975:415-431

4. Eadie MJ. Olivo-ponto-cerebellar atrophy (Menzel type). In: Vinken PJ, Bruyn GW, eds. Handbook of clinical neurology. Amsterdam: North-Holland, 1975:433-449

5. Holmes G. A form of familial degeneration of the cerebellum. Brain 1907;30:466-489

6. Greenfield JG. The spino-cerebellar degenerations. Oxford, England: Blackwell, 1954

7. Weber FP, Greenfield JG. Cerebello-olivary degeneration: an example of heredofamilial incidence. Brain 1942;65:220-231

8. Marie P, Foix C, Alajouanine T. De l'atrophie cérébelleuse tardive à prédominance corticale. Rev Neurol 1922;38:8491082

9. Duvoisin RC. An apology and an introduction to the olivopontocerebellar atrophies. In: Duvoisin RC, Plaitakis A, eds. The divopontocerebellar atrophies. New York: Raven, 1984
10. Liversedge LA, Emery V. Electroencephalographic changes in cerebellar degenerative lesions. J Neurol Neurosurg Psychiatry $1961 ; 24: 326-330$

11. Gilroy J, Lynn GE. Computerized tomography and auditory evoked potentials: use in the diagnosis of olivopontocerebellar degeneration. Arch Neurol 1978;35:143-147

12. Wadia NH, Irani P, Mehta L, Purohit A. Evidence of peripheral neuropathy in a variety of heredo-familial olivo-ponto-cerebellar degeneration frequently seen in India. In: Sobue I, ed. Spinocerebellar degenerations. Tokyo: University of Tokyo Press, 1980

13. McLeod, JG, Evans W. Peripheral neuropathy in spinocerebellar degenerations. Muscle Nerve 1981;4:51-61

14. Plaitakis A, Nicklas WJ, Desnick RJ. Glutamate dehydrogenase deficiency in three patients with spinocerebellar syndrome. Ann Neurol 1980;7:297-303

15. Plaitakis A, Berl S, Yahr MD. Abnormal glutamate metabolism in an adult onset degenerative neurological disorder. Science 1982;216:193-196

16. Plaitakis A, Berl S, Yahr MD. Neurological disorders associated with deficiency of glutamate dehydrogenase. Ann Neurol 1984;15:144-153

17. Duvoisin RC, Chokroverty S, Lepore F, Nicklas WJ. Glutamate dehydrogenase deficiency in patients with olivopontocerebellar atrophy. Neurology 1983;33:1322-1326

18. Chokroverty S, Khedekar R, Derby B, et al. Pathology of olivopontocerebellar atrophy with glutamate dehydrogenase deficiency. Neurology 1984;34:1451-1455

19. Finocchiaro G, Taroni F, Pandolfo M, Di Donato S. Glutamate metabolism alterations in dominant OPCA. Ital J Neurol Sci 1984; 2 (suppl 4):134-140

20. Finocchiaro G, Taroni F, Di Donato S. Glutamate dehydrogenase in olivopontocerebellar atrophies: leukocytes, fibroblasts, and muscle mitochondria. Neurology 1986;36:550-553

21. Konagaya $Y$, Konagaya $M$, Takayanagi T. Glutamate dehydrogenase and its isozyme activity in olivopontocerebellar atrophy. I Neurol Sci 1986;74:231-236

22. Gilman S, Markel DS, Koeppe R, et al. Cerebellar hypometabolism in olivopontocerebellar atrophy detected by positron emission tomography. Neurology 1986;36:230

23. Gilman S, Markel DS, Koeppe RA, et al. Olivopontocerebellar atrophy studied with positron emission tomography. In: Daroff R, Conomy J, eds. Contributions to contemporary neurology. Stoneham: Butterworths (in press)

24. Ehrenkaufer RE, Potocki JF, Jewett DM. Simple synthesis of F-18-labeled 2-fluoro-2-deoxy-D-glucose: concise communication. J Nucl Med 1984;25:333-337

25. Phelps ME, Huang SC, Hoffman EJ, et al. Tomographic measurement of local cerebral glucose metabolic rate in humans with (F-18) 2-fluoro-2-deoxy-D-glucose: validation of method. Ann Neurol 1979;6:371-388

26. Hawkins RA, Mazziotta JC, Phelps ME, et al. Cerebral glucose metabolism as a function of age in man: infuence of the rate constants in the fluorodeoxyglucose method. J Cereb Blood Flow Metab 1983;3:250-253

27. Gilman S, Markel DS, Koeppe RA, et al. A comparison of CT and PET findings in olivopontocerebellar atrophy. Ann Neurol $1986 ; 20: 121$

28. Konigsmark BW, Weiner LP. The olivopontocerebellar atrophies: a review. Medicine 1970;49:227-241

29. Weiner LP, Konigsmark BW. Hereditary disease of the cerebellar parenchyma. Birth Defects Original Article Series $1971 ; 7: 192-196$ 